\begin{tabular}{|l|l|}
\hline Filosofía y pensamiento crítico latinoamericano de la actualidad & Titulo \\
\hline Magallón Anaya, Mario - Autor/a; & Autor(es) \\
\hline $\begin{array}{l}\text { De Raíz Diversa. Revista Especializada en Estudios Latinoamericanos (Vol. 1 no. 1 } \\
\text { abr-sep 2014) }\end{array}$ & En: \\
\hline México D.F. & Lugar \\
\hline $\begin{array}{l}\text { Programa de Posgrado en Estudios Latinoamericanos, Universidad Nacional } \\
\text { Autónoma de México }\end{array}$ & Editorial/Editor \\
\hline 2014 & Fecha \\
\hline $\begin{array}{l}\text { Fenomenología; Pensamiento crítico; Teoría crítica; Filosofía crítica; Ontología; } \\
\text { América Latina; Caribe; }\end{array}$ & Colección \\
\hline Artículo & Temas \\
\hline "http://biblioteca.lacso.edu.ar/Mexico/ppel-unam/20160614015135/Magallon.pdt" & Tipo de documento \\
\hline $\begin{array}{l}\text { Reconocimiento-No Comercial-Sin Derivadas CC BY-NC-ND } \\
\text { http://creativecommons.org/licenses/by-nc-nd/2.0/deed.es }\end{array}$ & URL \\
\hline
\end{tabular}

Segui buscando en la Red de Bibliotecas Virtuales de CLACSO

http://biblioteca.clacso.edu.ar

Consejo Latinoamericano de Ciencias Sociales (CLACSO)

Conselho Latino-americano de Ciências Sociais (CLACSO)

Latin American Council of Social Sciences (CLACSO)

www.clacso.edu.ar

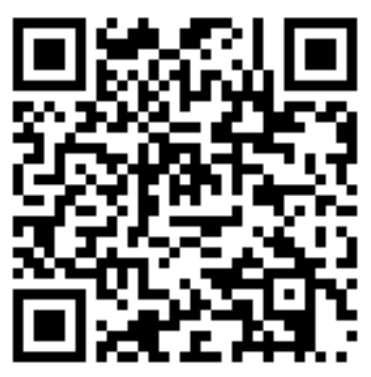




\section{Filosofía y pensamiento crítico latinoamericano de la actualidad}

Mario Magallón Anaya *

Resumen. La filosofía y el pensamiento crítico desde nuestra América han incorporado a nuestro filosofar, conceptos y categorías filosóficas provenientes de muy variadas tradiciones, algunas veces opuestas y otras contradictorias, tanto de las naciones de la región latinoamericana y caribeña, como del resto del mundo, especialmente del Occidente europeo. Sin embargo, esta diversidad de ideas de múltiple origen constituyen, hasta la actualidad, el instrumento del pensar filosófico-crítico sobre la realidad sociohistórica latinoamericana y caribeña; lo cual de ningún modo puede resultar sospechoso y extraño en el marco del pensamiento latinoamericano actual, como lo creen algunos filósofos sudamericanos y mexicanos.

Palabras clave: Filosofía, pensamiento, logos, fenomenología, ontología.

Aвstract. The philosophy and critical thinking from our America has sought to incorporate philosophical categories and concepts from a broad traditions's range. Sometimes contradictory and opposite, others even conflicting. Namely, we have been taken concepts, categories and notions from Western Europe. Indeed, this multiple origin of ideas nowadays constitutes the main tool of the philosophical and critical thinking on Latin American and Caribbean sociohistorical reality. Our work here is to compare the arguments in favor of our own diverse tradition with those that suggest the practice as suspicious and even strange.

KEYWORDS: Philosophy, thought, logos, phenomenology, ontology.

Recibido: 06 de agosto de 2013. ACEPTAdo: 08 de enero de 2014.

\section{EL PROBLEMA DE LA FILOSOFÍA Y DEL PENSAMIENTO CRÍTICO}

\section{$\mathrm{L}$} as miradas actuales de la filosofía en América Latina y el Caribe obligan a repensar el carácter crítico y de pensamiento, no sólo de una región geográfica, sino del mundo entero para aceptar de una vez por todas que la reflexión crítica es el modo propio de ser de la filosofía y del pensa-

* Investigador del CIALC, <mariom@unam.mx>. 
miento. Porque la crítica es, de cierta forma, la base fundamental de la práctica del pensar filosófico y la consecuencia del filosofar y de su producto: la filosofía.

La filosofía y el pensamiento crítico desde nuestra América han buscado incorporar a nuestro filosofar, conceptos y categorías filosóficas provenientes de muy variadas tradiciones filosóficas, algunas veces opuestas y otras contradictorias, tanto de las naciones de la región latinoamericana y caribeña, como del resto del mundo, especialmente del Occidente europeo. Esta diversidad de ideas de múltiple origen son, hasta la actualidad, el instrumento del ejercicio del pensar filosófico-crítico sobre la realidad sociohistórica latinoamericana y caribeña, lo cual de ningún modo puede resultar sospechoso y extraño en el marco del pensamiento latinoamericano actual, como lo creen algunos filósofos sudamericanos y mexicanos. La filosofía y el filosofar se hacen a partir de una realidad situada, donde frecuentemente la noción de crítica crea una especie de desestructuración de la tradición y del legado histórico-filosófico de nuestra América, de las filosofías conservadoras, de las tradicionales e, incluso, de las revolucionarias: socialistas, anarcosocialistas y marxistas. Esto se hace presente en tendencias, escuelas y corrientes. Así, puede decirse que la filosofía y el pensamiento crítico en general se alejan con reticencia de la fenomenología, como del mundo de la cultura filosófica, política e ideológica tradicionales, para replantear un nuevo horizonte de la criticidad analítica en el orden teórico, epistémico y óntico de la realidad. Empero, la teoría crítica de las ideologías y de las condiciones de existencia, como las del mundo de la vida, están demarcadas por la fenomenología y la hermenéutica.

La filosofía y el pensamiento crítico aluden al pensamiento inaugurado por la filosofía de Marx y proseguido por la Escuela de Frankfurt; la fenomenología hermenéutica refiere - en especial- a la obra tardía de Husserl, titulada Meditaciones cartesianas, y trabajos posteriores desarrollados por sus discípulos Schutz y Luckmann, cuyo fin era su reinstalación y resemantización inter y transdisciplinaria, en las tres últimas décadas del siglo XX para ser considerado como la cuestión central de la teoría de la acción comunicativa de Jürgen Habermas.

En nuestra región, y en el resto del mundo, puede decirse que los filósofos y los académicos, desde diversas corrientes y escuelas filosóficas, han entendido el ejercicio del filosofar y del pensar filosófico como exclusivo de su hacer y su quehacer, desde ciertos cánones academicistas y 
"profesionales", donde transita el mundo de la vida; es decir, de las condiciones de existencia social y material a la producción cultural y simbólica, lo cual incide en la inter y transculturalidad, en el multiculturalismo, las filosofías posmodernas y poscoloniales, en el ascetismo, en el falocentrismo, en el logocentrismo, en el autoritarismo, hasta cuestionar el carácter represivo y autoritario de la modernidad europea como la aceptación de la pluralidad filosófico-política, hasta arribar a los grandes debates filosóficos, políticos y culturales del mundo.

En la actualidad, se ha replanteado el regreso a las ontologías del presente a la metafísica, a la construcción ontológica y epistémica de los saberes, a los grandes relatos totalizadores estructurados desde la lógica del discurso. Adjunta se encuentra la concepción de la filosofía de la vida cotidiana, del ethos, donde se entremezclan y coluden formas ideológicas, de representación, de concepciones del mundo y de la vida, como del análisis crítico de la practicidad fenoménica de la filosofía y del pensamiento para establecer, asimilar y asumir las diversas tradiciones filosóficas y políticas a las propias, constituyendo en algunas ocasiones novedosas formas de pensar y de entender la realidad. Empero, la reflexión sobre ello muestra que casi no se agrega nada al propio filosofar ni a la filosofía, salvo en la interpretación, resemantización y reconstrucción conceptual de las terminologías novedosas, que actualmente no han revolucionado -sólo parcialmente- a la filosofía y al pensamiento. Por ello, es necesario radicalizar la crítica y revolucionar dicha filosofía y el pensamiento para que transformen y revelen los modos de conciencia de la realidad de la existencia material y social.

La crítica a las disciplinas aparece con Habermas, Morin, Bourdieu, Wallerstein, Zemelman, etcétera. A su lado, se encuentra la crítica desestructurante, deconstructiva y reconstructiva de Boaventura de Sousa Santos, que consiste en el descrédito de la filosofía y la epistemología occidental europea. Desde esa tradición, el autor no parte del "horizonte sureador" (como la tendencia epistemológica de reestructuración disciplinaria, inter, trans y multidisciplinaria) consecuencia de la proliferación de "nuevos tipos" de pensamiento y de construcciones conceptuales, así como prácticas de escritura, de diálogo, de comunicación, de discrepancia, de negociación y de entendimiento dialéctico, aunque no siempre de síntesis. 
En la actualidad, se retorna a las filosofías tradicionales en el mundo, junto a sus corrientes y escuelas, con nuevos lenguajes discursivos y formas expresivas. Es el regreso a las filosofías prácticas como la ética, la filosofía política, la filosofía de la educación, la antropología filosófica, la historia de las ideas, la filosofía de la historia, la religión, de las filosofías y de teologías de la liberación, etcétera. ${ }^{1}$

Después de los grandes remezones de las éticas y de las filosofías indoloras posmodernas sin compromiso y sin reglas, sin principios reguladores de las construcciones discursivas y del pensamiento crítico, socialmente construido; porque toda producción humana se materializa en las formas expresivas y simbólicas que orientan y señalan los modos de hacer y de producir filosofía, ciencia, cultura, civilización, pensamiento e ideas; de entender y de concebir al ser humano en el mundo, en la vida, en la producción de la existencia y de cultura.

Ante este horizonte conceptual inter y transdisciplinario en el mundo occidental europeo y en algunas otras regiones del planeta, se hace presente la aparición y un "respiro" para iniciar la marcha de regreso a la modernidad renovada, alternativa resemantizada, que busca superar el carácter autoritario para recuperar y transgredir las concepciones imperiales de la modernidad y posmodernidad europeas que habían liquidado el fin de la historia, la metafísica, las ideologías, la ontología y el sujeto, allí donde el tiempo se estatiza y se constituye ideológicamente en un permanente presente, donde el pasado y el futuro ya no existen, tampoco el progreso, menos aún la ética o la filosofía política.

En este sentido, comparto la siguiente afirmación de Fredric Jameson:

El resurgimiento del concepto de modernidad es un intento de resolver ese problema: en una situación en la cual han caído en descrédito la modernización, el socialismo, la industrialización (en particular la modalidad anterior de la industria pesada, previa a la computación), el prometeísmo y la "violación de la naturaleza" en general, puede sugerirse aún que los llamados países subdesarrollados querrían tal vez aspirar simplemente a la "modernidad" misma. Poco importa que los Estados naciones del mundo viables del mundo de nuestros días hayan sido desde hace mucho "modernos" en todos los aspectos imaginables, Occidente tiene algo que nadie más posee, pero el resto debería desear para sí. ${ }^{2}$

1 Cfr. Fredic Jameson, Una modernidad singular. Ensayo sobre la ontología del presente, Argentina, Gedisa, 2006.

2 Ibid, p. 18. 
Es importante señalar que la tradición latinoamericana y caribeña en la filosofía y el pensamiento se aleja de la concepción moderna europea y propone otras salidas desde la llamada modernidad alternativa, como la expresión plural y polisémica de sentido desde un núcleo problemático. Esto es, más allá del desarrollismo de Jameson, donde el centro común con la filosofía europea es la razón humana, común al ser humano en contra del principio autoritario de la razón imperial excluyente.

Es preciso insistir, desde el horizonte de la filosofía y de la modernidad, que el pensar y la filosofía crítica requieren y necesitan del análisis que vaya más allá de los modos de concebir y entender la realidad para transformarla. Esto es, poner en cuestión los supuestos de las escuelas, corrientes y doctrinas filosóficas para reorientar filosóficamente el hacer y el quehacer desde un pensar crítico.

\section{PASADO-PRESENTE-FUTURO DEL PENSAMIENTO FILOSÓFICO CRÍTICO EN NUESTRA AMÉRICA}

La tradición cultural de América Latina y el Caribe de la última década del siglo XX estuvo alejada y excluida de la tesis del literato mexicano universal, Alfonso Reyes, cuya hermosa metáfora parafraseo a continuación: México, y por consiguiente América Latina y el Caribe, había llegado al convivio de la historia y de la cultura occidental cuando los comensales (europeos) ya se habían levantado de la mesa. Es decir, allí donde sólo habían quedado las migajas del festín de la cultura occidental.

Un siglo antes de lo dicho por Reyes, Hegel dijo que nuestra América "es el reflejo de ajena vida". Sin embargo, son concepciones eurocéntricas excluyentes de una visión occidental culturalista de origen imperial metropolitano. Esta forma de ver y percibir la región latinoamericana nulifica lo más valioso de América Latina: la historia, la filosofía, la literatura, el arte y la cultura en general, pues partiendo de la perspectiva eurocéntrica, nada de lo nuestro hasta la actualidad es suficientemente valioso.

El siglo XX fue el más violento y tormentoso en la historia de la humanidad: dos grandes guerras mundiales, movimientos revolucionarios independentistas, anticoloniales, asonadas violentas, represiones militares, luchas armadas, políticas totalitarias y fascistas, hasta llegar a la actualidad, donde se da la redefinición de formas y prácticas imperiales y neoimperiales ejercidas por los países del Norte contra el resto del mundo subdesarrollado, 
pobre, explotado y marginado. La mundialización o globalización de la economía y la aplicación de la utopía total del neoliberalismo han roto los paradigmas sociales del Estado de bienestar de raíz liberal y económica keynesiana; de la misma forma ha desaparecido el "socialismo real" o, más bien, "histórico".

Conceptos como: Filosofía, Utopía, Razón, Totalidad, Ser, Dios, Historia, Sujeto, Metarrelatos, etcétera, han sido fragmentados y divididos en estructuras discursivas micros, incapaces de explicar la totalidad del ente, de la realidad histórica y del sistema-mundo. Enseñoreados de forma globalizada, en la segunda mitad del siglo XX confluyeron el neoimperialismo y el neocolonialismo, los cuales, donde la "sociedad abierta" liberal y conservadora de Karl Popper, que de tan abierta se ha cerrado a cualquier otra opción alternativa del "pensamiento único" del neoliberalismo globalizado mundial y la posmodernidad y la poscolonialidad, van quedando en el olvido para volver a los discursos duros, la metafísica, la ontología, la epistemología, entre otros. Paralelamente, se estudia el problema de la democracia en el mundo y se replantean nuevas formas de entender lo político y la democracia. Este choque de formas culturales no ha dado la síntesis que permita la reconstrucción del horizonte político, social, democrático y cultural de nuestra América.

La globalización ha generado en las zonas urbanas de las principales ciudades de las naciones latinoamericanas, caribeñas y del sistema-mundo, "el espíritu de la tribu", configurado por la resistencia y la defensa contra la exclusión y la coptación de las formas unidimensionales de la economía globalizada y neoliberal, que cada vez más, limitan la libertad de pensamiento, de razonar, de actuar, de imaginar mundos posibles más humanos y justos.

En América Latina y el Caribe están resurgiendo movimientos sociales nacionales, regionales y continentales, que demandan el respeto de los derechos sociales, políticos, económicos y culturales, como la diversidad de género y la defensa de los derechos humanos. En todo ello, se buscan nuevas alternativas de participación y la redefinición de nuevas tendencias en la reconstrucción epistemológica y ontológica de la realidad. Justo ahí, se conjugan formas críticas en relación dialógica horizontal equitativa, solidaria y democrática. Es la crítica de la alteridad excluyente e inequitativa de las prácticas sociales en las construcciones discursivas y en la argumentación social y política. En un mundo así, la filosofía como 
ejercicio libre, autónomo, racional y crítico, debe oponerse a la Razón totalitaria e imperial, porque no puede ser cómplice de las condiciones de existencia de las mayorías y de las minorías excluidas latinoamericanas y del sistema-mundo. Menos aún, se puede reducir la labor filosófica al trabajo de cubículo; debe ser un trabajo reflexivo, analítico y éticamente responsable.

Por lo mismo, la filosofía entre nosotros debe asumir el compromiso histórico que le corresponde, o sea, de denuncia y crítica de las condiciones históricas de existencia de los latinoamericanos y caribeños, así como también del resto del género humano. Sin embargo, ello no deberá entender a la filosofía como ideología, menos aún, como meta-discurso emancipatorio de las necesidades políticas, directas e inmediatas; más bien, debe tomar conciencia de que su propia razón de ser es inseparable del mundo en que se hace, del mundo que la niega, allí donde no existen las condiciones indispensables para su libre ejercicio.

La filosofía, además de preocuparse por afinar el instrumental teórico, conceptual y metodológico, debe considerarse como algo vital que sirva para la crítica, desmitificando y conociendo la realidad latinoamericana; porque no se puede filosofar de espaldas a la realidad de nuestro continente. Por esto mismo se debe procurar no caer en la abstracción obstaculizante que impide ver a los hombres concretos como seres situados en una realidad sociohistórica que requiere ser transformada.

Es necesario reconocer que la filosofía está permeada por la ideología, pero también por las ciencias sociales y naturales; señalar también que la realidad en sí misma no es filosófica, pero como acertadamente escribe Adolfo Sánchez Vázquez, "la filosofía sólo puede existir si existen las condiciones extrafilosóficas reales que la hacen posible".

El marxismo, el socialismo y las izquierdas en nuestra región han llegado a ser no sólo una filosofía y una ciencia social de lucha política, sino revolucionaria, teórica y prácticamente. Porque fue una explicación científica del mundo social y humano y una ideología implícita de una filosofía de la praxis latinoamericana. La teoría y la práctica se dan en la relación complementaria entre la teoría de la praxis.

Henri Lefebvre, con una concepción altamente práxica, considera que la práctica sin teoría es un disparate, ya que la praxis creadora y revolucionaria no excluye la teoría que ésta anima y verifica; comprende tanto

3 Adolfo Sánchez Vázquez, Sobre filosofía y marxismo, México, UAP, 1983, p. 99. 
la decisión teórica como la decisión de actuar. ${ }^{4}$ La consistencia lógica abstracta, la teoría divorciada de la actividad social y la verificación práctica no tienen valor. Es decir, se entiende que "la esencia del hombre es social y la esencia de la sociedad es la praxis: abstraída de la praxis, la teoría sólo puede atascarse en el misticismo y la mistificación". ${ }^{5}$

El marxismo y el socialismo latinoamericanos son teorías filosóficas y sociales complejas. "Donde el objetivo de la complejidad es, por una parte, unir (contextualizar y globalizar) y, por otra, recoger el reto de la incertidumbre". No se busca decir que con la incertidumbre se expulsa la certidumbre y, menos aún, la lógica de los procesos para permitirse toda trasgresión. La construcción del universo social y del conocimiento social en América Latina se caracteriza por su complejidad, sus contradicciones y antagonismos; sus diversidades y negaciones. Sin embargo, existe en el marxismo de América Latina una veta filosófica muy clara que no ha sido reconocida por los historiadores de la filosofía latinoamericana. Es decir, no reconocen "que el marxismo ha sido un interlocutor permanente de muchos filósofos y corrientes". ${ }^{2}$ Aunque no siempre lo hicieron de forma abierta, ni hacían referencia a éste como fuerza teórica, epistemológica y crítica dialéctica que analiza las condiciones de existencia de los explotados, marginados, etnias, mujeres, grupos dominantes, etcétera.

El pensador crítico-marxista Pablo González Casanova, en un texto clásico, al cual recurrimos de nuevo para analizar y comprender las consecuencias del capitalismo transnacional y global en la región, apunta que:

Con el marxismo, surge por primera vez como constitutiva "una relación social determinada", que tiene varias características, en cuanto a su carácter constitutivo, y en cuanto a su delimitación o determinación. La relación social es constitutiva de otras filosofías es histórica y contradictoria. En otras filosofías toda entidad constitutiva es metahistórica -incluso el positivismo y el empirismo- y coherente, en el sentido de que no representa la lucha. El conflicto, lo irracional, sino uno de sus términos, el bien de la razón. En el marxismo la relación social es constitutiva, pero además histórica, contradictoria y concreta. ${ }^{7}$

${ }^{4}$ Cfr. Henry Lefebvre, The Sociology of Marx, Londres, Penguin, 1972, p. 54.

5 Ibid, p. 33. (traducción propia).

6 Gabriel Vargas Lozano, ¿Qué hacer con la filosofía en América Latina?, México, UAMIztapalapa/Universidad Autónoma de Tlaxcala, 1990, pp. 182-183.

7 Pablo González Casanova, Sociología de la explotación, México, Siglo XXI, 1978, p. 26. 
No obstante, en América Latina y el Caribe y en el resto del sistema-mundo nunca existió una sola versión del socialismo tal como lo creyeron los doctrinarios ortodoxos; más bien, existían varios socialismos e izquierdas. Sin duda, esto lleva a un debate teórico-epistémico que se coloca por encima de posiciones ideológicas y reconoce que el método marxista no es doctrinario, sino científico dialéctico. ${ }^{8}$ Empero, la dialéctica no es lógica, es un proceso de desarrollo teórico sobre una totalidad concreta de lo real, de las relaciones sociales e históricas.

La articulación entre ciencia y dialéctica consiste en la posible integración del producto científico dentro del cuadro dialéctico de la práctica social para constituir una teoría social compleja, pues la teoría en sí misma - en principio- es el resultado de varias prácticas y de múltiples determinaciones y oposiciones.

Por esto mismo puede decirse que "la tradición marxista no es una tradición teórica pura. Es una tradición política, una intervención consciente y organizada en la lucha de clases, sobre la base de un fundamento científico en sentido estricto y un fundamento todavía más amplio de carácter filosófico". ${ }^{9}$

Cuando se reflexiona sobre las causas de la disolución del socialismo real, se debe considerar como primer punto las cuestiones relativas a las relaciones generales entre planificación socialista y la autogestión; un segundo punto es la interacción, por un lado, entre el capitalismo avanzado y el capitalismo tardío de Jürgen Habermas; y por el otro, el liberalismo y la socialdemocracia. Sobre la cuestión referida al anticapitalismo contemporáneo, en muchas ocasiones no es de inspiración socialista, más bien, neoconservadora; sin embargo, se constituye en una fuerza social e intelectual importante cada vez más influyente y dominante.

La apertura indiscriminada de las economías nacionales al proceso de internacionalización económica del capitalismo mundial no corrigió el desequilibrio externo, pero impuso graves retrocesos en la diversificación y en los niveles de actividad de las economías internas. Además, las medidas encaminadas a corregir los supuestos excesos en la atención de demandas sociales básicas únicamente acentuaron las tendencias recesivas y el empobrecimiento de amplias capas de la población de las naciones,

8 Cfr. Sergio Bagú, Tiempo, realidad y conocimiento, México, Siglo XXI, 1982.

9 Gabriel Vargas Lozano, Juan Mora Rubio y Jorge Rendón Alarcón, "Entrevista. Manuel Sacristán habla para Dialéctica. El marxismo ha sido derrotado", Dialéctica, núm. 13, p.117, junio de 1983, México. 
además de los costos en el plano político, el de los derechos sociales y humanos fundamentales.

Al observar la realidad global desde diversos ángulos, es posible decir que las condiciones objetivas que legitiman la aspiración y determinan la necesidad de transformaciones económicas, políticas y sociales del orbe rebasan los límites del neoliberalismo. Por lo tanto, se requiere buscar nuevas salidas más justas, equitativas, democráticas y humanas.

Hoy, en la realidad socialista de Cuba y en las perspectivas generadas por las revoluciones centroamericanas de raíz izquierdista, no se percibe su influencia en el plano subjetivo de la conciencia social y política latinoamericana, tanto a nivel nacional como internacional; no están a la orden del día en los movimientos sociales y las luchas populares de género, ecologistas, de mujeres, etcétera.

Es decir, cuando son tan evidentes los signos de la crisis, del agotamiento y agrietamiento de las potencialidades del capitalismo global, se debe perseverar en la continuidad del desarrollo de las fuerzas productivas en la región desde un proyecto social colectivo. Ahora se necesita más, pues se ha abandonado el socialismo y, con ello, dicho proyecto.

La realidad histórica muestra la atomización de grupos, partidos de izquierda y organizaciones colectivas de trabajadores. Incluso, algunos que habían sido sus ideólogos han cambiado de bando, otros se han replegado o "metamorfoseado", adaptándose a las circunstancias imperantes, donde domina más el interés personal que el social.

Hace más de 30 años, Pedro Vuskovic señaló lo siguiente sobre el problema de las izquierdas y los partidos políticos, que hasta hoy tiene vigencia de la realidad diluyente:

En muchos países de la región, los partidos políticos de la izquierda latinoamericana exhiben las características de pronunciada atomización y dispersión, en algunos casos aparecen escasamente articulados con las masas, con poquísima gravitación en los procesos políticos globales, carentes de una propuesta certera y coherente que identifique las aspiraciones populares y movilice toda la fuerza social que potencialmente podrían representar. ${ }^{10}$

10 Pedro Vuskovic, "Crisis del desarrollo capitalista y perspectivas del socialismo en América Latina”, Dialéctica, núm. 20, p. 31, diciembre de 1988, México, Escuela de Filosofía, Universidad Autónoma de Puebla. 
Cuestiones como éstas muestran que el origen de dichos problemas se encuentra en la represión sistemática que han padecido en los diversos países del mundo, los movimientos sociales y políticos de los grupos y partidos de izquierda en el debate ideológico constante, en el que hasta la actualidad se desenvuelven.

Por las razones expuestas, es ineludible estudiar más a fondo el pensamiento crítico, los movimientos sociales, las políticas de la filosofía de cada región en el mundo; la filosofía política y la eticidad en América Latina y el Caribe, como los sujetos sociales y su participación en la transformación de las luchas populares por una realidad sociohistórica más humana y justa.

Es necesario participar en la reflexión teórico-práctica para poder entender los procesos reales e históricos; reconceptualizar, categorizar y resemantizar la teoría social, la filosofía política y la eticidad de forma creativa para reinventar y reestructurar las propuestas económico-sociales y políticas de un pensar crítico y analítico renovado. Esto es, tomar conciencia de que el pasado cuenta, pero no debe ser un lastre que obstaculice el análisis y la teorización de las luchas políticas y sociales, y la transformación de las sociedades injustas, desiguales y antidemocráticas, por otras más justas, igualitarias y democráticas.

Todo esto ha sido el resultado de reflexiones hechas alrededor de un sujeto filosofante situado en un horizonte histórico de sentido y de significación. De tal manera que conocimiento, razón, juicio, argumento y formas discursivas no pueden ser consideradas construcciones puras e incontaminadas al modo positivista o neopositivista; más bien, están dialécticamente relacionadas, mediadas por la sujetividad, o sea, por un sujeto que analiza y reflexiona críticamente las realidades simbólicas, ontológicas, teóricas, filosóficas, y todas deberán ser interpretadas y resemantizadas para producir nuevas construcciones epistémicas y significativas.

\section{DEMOCRACIA Y CIUDADANÍA EN NUESTRA AMÉRICA}

El mundo de nuestros días vive una época de cambio como en toda fase de transición democrático-política y de cambio de "espíritu de la época". Se entremezclan y confunden viejas y nuevas maneras de concebir y de actuar sobre la realidad sociohistórica. Así, la globalización no sólo ha significado una transformación profunda en el plano económico, también abarca otras dimensiones de la vida social y humana. 
Lo anterior se presenta al lado del tránsito del mercado global: la circulación hacia redes mundiales de intercambio de relación intelectual y cultural, donde se observa la constitución de novedosas formas de interacción entre grupos humanos geográficamente distantes y entre las relaciones de las llamadas redes de ciudadanos interesados en las temáticas específicas que inciden en la acción de los gobiernos de los Estados nacionales en el sistema mundial.

Además, en este mundo global, se ha dado la sustitución de la estructura productiva de base nacional, por los "sistemas fabriles mundiales"; así pues, asistimos a la transformación de las identidades nacionales, las cuales se han visto orilladas a incorporar elementos simbólicos. Esto no se había observado hasta la actualidad y se consideraba como algo foráneo y exótico.

Sin embargo, la realidad mundial está transida de violencia y de consumismo, como si esto cerrara la posibilidad de cambiar el espíritu del siglo XXI. Parece imposible reorientarlo hacia una ética política con valores democráticos, garantizadores de la convivencia humana en armonía con la Naturaleza, con el oikos, con la Casa de Todos. Ello implica defender el respeto y la dignidad humana entre la diversidad del género humano. No obstante, la existencia social, la naturaleza humana, situada ónticamente en la historicidad, está atravesada y penetrada por la contradicción y las oposiciones, por el pólemos en la práctica dialéctica procesual e histórica.

Por ello, todos los campos del saber, de la ciencia, la tecnología, la política, las ciencias sociales, las ciencias naturales y las humanidades requieren reorientar su hacer y su quehacer para garantizar (aunque sea mínimamente) el equilibrio de las relaciones humanas en el sistema-mundo, el capitalismo y las economías, intentando respetar la diversidad cultural humana, histórica y social, lo cual implica reconocer que la realidad mundial está conformada por una pluralidad de escenarios que tienen en común el problema de la comprensión y el entendimiento éticamente responsable, más allá de las formas egoístas del capitalismo global, que de forma irracional crece y mediatiza todo lo valioso éticamente humano.

Al final de la primera década del siglo XXI encontramos que:

En América Latina la crisis amenaza con la desestabilización. En varios países existe el peligro de perder ciertos avances recientemente obtenidos. Como algunos recuerdan, los fantasmas del pasado parecen volver. Luego de un período de bajo crecimiento hasta los años noventa e inicio de la 
década actual, la región tuvo una fuerte recuperación, especialmente a partir de 2003, con buenos resultados económicos [...] Ha sido notable el incremento del producto por habitante, destacando países como Argentina y Venezuela. Esto se debió a la puesta en práctica de determinadas acciones económicas que en diversa medida tomaron distancia de las propuestas del Consenso de Washington. Pero también a la existencia de condiciones externas favorables, muy particularmente al aumento de los precios de las materias primas, aunque de manera diferente según los países. En 2009, los resultados son diferentes y los pronósticos más recientes señalan que la región en conjunto está entrando en recesión. ${ }^{11}$

Se trata de una época de derrumbe, transformación, crisis y grandes incertidumbres, puede decirse con toda certeza que los paradigmas de la Ilustración se han agotado y, por lo menos hasta la actualidad, no se vislumbran en el horizonte fórmulas de cambio o de reconstrucción para la crisis. Quizá se deba a que éstas sólo han sido consideradas como mera ilusión ideológica, limitando la posibilidad de entender el cambio y su aplicación para la nueva y compleja realidad vivida en el mundo globalizado.

En la actualidad histórica, se tiende a poner en tela de juicio a los grandes referentes de lo social, ya se trate de las utopías sociales que tan significativamente marcaron el siglo XX, o bien, la noción de desarrollo social como un encadenamiento inacabado de progresiones hacia un rumbo incierto e inalcanzable.

La incredulidad reinante en la actitud posmoderna ha invadido la ciencia y la tecnología, más allá de los postulados de la física tradicional del tiempo y de la lógica lineal, que no sólo habían presidido el razonamiento y el método científico, sino impuesto su sello al conjunto de la vida social para plantear teorías caóticas y de la fragmentación, abriendo nuevas vías para entender el mundo actual.

Puede decirse que ya no existe el escepticismo creativo e imaginativo que siempre había impulsado las transformaciones del pensamiento. Éstas ahora son concebidas simple y llanamente como descreimiento, incredulidad, indisposición a validar la vieja lógica científica, como un juego entre la búsqueda y el azar. De esta forma, la sociedad pierde la confianza en la capacidad del Estado-nacional para garantizar el progreso material de

11 Gregorio Vidal, Arturo Guillén y José Déniz (coords.),"Introducción: América Latina y sus opciones en el curso de la crisis mundial", Desarrollo y transformación: opciones para América Latina, España, FCE, 2010, p. 25. 
la sociedad. Así, se hace presente la ruptura de los símbolos de autoridad democrática y el retorno de la ciudadanización a la esfera individual.

Es un hecho innegable que la globalización y el neoliberalismo han erosionado la representatividad de los Estados nacionales y los medios tradicionales de socialización política.

Conviene no llevar demasiado lejos el problema, a pesar del escepticismo e incluso el desaliento que en la época contemporánea permea la posmodernidad. En el mundo global, el Estado y el gobierno son aún la única instancia ante la cual los ciudadanos y los electores pueden reclamar justicia, responsabilidad y cambio, pues, la mera idea de la alianza con los consorcios para asumir funciones estatales es ilusoria.

Empero, es necesario señalar que la construcción de la Nación no se reduce únicamente al dato ontológico, porque su aparición se encuentra histórica y socialmente determinada por la práctica, consecuencia de las formas de organización social, colectiva, política, cultural y económica, dentro de un espacio geográfico. Este fenómeno se da en épocas de transformación y de cambio, que requieren redefinir las identidades sociales y políticas. ${ }^{12}$

Las sociedades políticamente organizadas tienen procedimientos para decidir respecto de su rumbo y el de todos sus integrantes. En las sociedades democráticas, el ejercicio del sufragio constituye el modo cierto y objetivo de integrar y reconocer lo que Rousseau denominó en el Contrato social, la voluntad general.

Para algunos, la democracia se reduce a un modelo de gestión política, con sus variantes más o menos participativas. Para otros, es un modo de vida definido por valores que afectan todos los ámbitos sociales y personales. Y para ello, son necesarias la pulcritud y la transparencia con que se organizan los procesos de los comicios, lo cual resulta fundamental para que los ciudadanos reconozcan el ejercicio del voto como mecanismo relevante de participación en los asuntos públicos y, del mismo modo, se reconozca en los gobernantes no sólo la legalidad, sino también legitimidad en su actuación o, según sea el caso, de forma inversa o contraria a ella.

12 Cfr. Claudia Wasserman, "Intelectuales y la cuestión nacional: cinco tesis respecto a la constitución de la nación en América Latina", en Antonio Escobar Ohmstede, Romana Falcón Vega y Raymond Buve (coords.), La arquitectura histórica del poder. Naciones, nacionalismos y Estados en América Latina. Siglos XVIII, XIX y XX, México, El Colegio de México/Centro de Estudios de Documentación Latinoamericano, 2010, pp. 116-117 y ss. 
Simultáneamente, las elecciones son un mecanismo de designación de los gobernantes, un espacio de expresión de ideas que buscan la aceptación mayoritaria de la sociedad y un medio para que el individuo tome parte y se comprometa en las decisiones fundamentales del conjunto social. Por ello, los procesos electorales son mucho más que el solo acto de depositar una boleta electoral en la urna.

La fase actual del desarrollo capitalista global se resume en una gigantesca concentración de poder trasladada de lo político a lo económico, a la erupción bursátil, a la economía especulativa, a la tecnología de las empresas transnacionales, a las ganancias de los capitales especulativos y a la producción económica exportada a países neoimperiales, lo que origina una mayor desigualdad entre el Primer Mundo y el ahora, mal llamado Tercer Mundo, de la mayoría de los países pobres del hemisferio sur del planeta.

Los resultados económicos del modelo neoliberal tienen un patrón económico real, que radica en por los menos dos indicadores: 1) el crecimiento que es capaz de lograr; y 2) la distribución del ingreso que ocasiona. Sin embargo, el neoliberalismo ha provocado una distribución del ingreso notoriamente más regresiva. A ello se suma una economía especulativa y financiera, que deriva en el desplome del salario real y el desempleo cada vez más creciente en todo el mundo. ${ }^{13}$

Por lo tanto, debemos señalar que:

El estancamiento y el desplome salarial no son casuales. Y debería quedar claro que la lógica objetiva del comportamiento del capital de préstamo y especulativo, conduce al estancamiento. Por lo mismo, si esto es lo que exige el sistema en cierta fase del desarrollo, lo congruente es que esta fracción del capital pase a ocupar los puestos del comando. ${ }^{14}$

La falta de una crítica razonada hacia el capitalismo global facilitó que la mayoría de los países lo asumieran como la única salida, después de la experiencia fracasada del "socialismo histórico", o más bien del "socialismo real”. Desde esta perspectiva, la globalización se presentó como la llave capaz de abrir todas las puertas, pero la mayoría de las veces ha sido indefinida, vaga, inconsistente y contradictoria.

13 Cfr. José C. Valenzuela Feijoó, Libertad y razón. Rousseau, Hegel, Marx, Santiago de Chile, LOM Ediciones/Universidad Metropolitana, 2006, p. 27.

14 Ibid, p. 29. 
El término globalización evoca un caudal de fenómenos y procesos sociales, cuya existencia es negada por algunos estudiosos. Mientras tanto, hay quienes cuestionan su supuesto carácter novedoso. En cambio, los que están a favor de dicho carácter divergen sobre el juicio de valor y, dentro de éste, se encuentran sus apologistas y muchos de sus críticos radicales.

En la mayoría de los países de América Latina y el Caribe los gobernantes no invierten en el desarrollo de la ciencia ni de la tecnología, menos aún, en la preparación de investigadores y científicos de alta calidad a través del financiamiento de la educación superior pública y privada; tienen poco interés por buscar mediante las humanidades, ciencias sociales y naturales el desarrollo para la producción de nuevas tecnologías para abatir la pobreza, la marginación, las enfermedades, el racismo, la exclusión, las formas autoritarias y totalizadoras, así como para garantizar la seguridad social para las mayorías y las minorías, sociales y políticas.

La sociedad actual ha encontrado que con el desarrollo de la ciencia, las nuevas tecnologías, las formas político-democráticas distributivas, equitativas y solidarias, se puede conducir a la producción de nuevos conocimientos y al mejoramiento de la vida social con justicia y equidad a través de la ampliación de nuevos aprendizajes que propicien formas de vida y de convivencia social en libertad y con justicia solidaria, pues ello haría posible tomar decisiones menos espontáneas y ligeras, y sí más previsoras, con proyectos y programas políticos, económicos y comunitarios que busquen superar las viejas formas políticas inmediatistas y de poco o nulo impacto social.

Empero, todo ello demanda mayor inversión en todos los niveles de la educación e investigación en sus múltiples campos: científicos, tecnológicos, sociales, económicos, políticos y culturales. Ante esto, se requiere de la creación de nuevas tecnologías para generar y producir mayor autonomía e independencia, con el fin de ir más allá del trabajo de producción de "maquila", o por encargo, para los países metropolitanos y neoimperiales.

Ante esta situación, en la primera década del siglo XXI, se plantea la necesidad de una política de Estado para la investigación científica, tecnológica y humanística, con el propósito de reformular un plan para el sistema nacional de educación superior y de investigación en general en los Estados latinoamericanos y de impulsar áreas estratégicas fundamentales en la mayoría de las diversas subregiones productivas de América Latina y el Caribe. El aludido proceder inevitablemente influirá en el crecimiento 
de la cultura científica; sin embargo, sólo será posible en la medida en que se garantice la inversión pública y privada en situación de equidad, justicia e igualdad solidaria en los propios países de la región latinoamericana y caribeña.

Cualquiera que sea la posición asumida en la toma de decisiones político-económicas, la globalización deberá ser vista no sólo en términos negativos sino también positivos, de oportunidades para todos. Ante ello, es importante tener cierta idea unificadora del género humano a través de la interconexión planetaria de todas sus partes constituyentes, dentro de la justicia, la equidad, la solidaridad, la libertad y la democracia colectiva y comunitaria. Sin embargo, la realidad vivida en los últimos 40 años ha potenciado y ejercido prácticas lesivas que atentan contra la humanidad, el medio ambiente y el equilibrio ecológico del planeta.

Así, la globalización está referida en algunos planos y niveles de la interconexión mundial, sobre todo en el ámbito económico, y se encuentra articulada en dos dimensiones: 1) en la extensión mundial y en el intercambio de mercancías y dinero; 2) en el desarrollo transnacional o de la globalización de los procesos productivos de las empresas.

Por tal razón, podemos decir que

lo que llamamos globalización no es más que la forma sobre la base de la cual el mundo se ha desplazado hacia la unidad. Pero el nuevo mapa del mundo resulta teóricamente comprensible sólo a la luz del carácter complejo y problemático de la distinción entre global y local, tanto que ahora deberemos quizá hablar de institucionalización global del mundo-vida y de localización de la globalidad. Considerado como conjunto, el campo global es una realidad multidimensional surgida de la comprensión de culturas conectadas a civilizaciones. El sistema-mundo no está, por lo tanto, guiado exclusivamente por la dinámica económica (como quería Emmanuel Wallerstein), sino también por el rol problemático del factor cultura; como consecuencia, no sólo el pluralismo cultural es de por sí un rasgo constitutivo de la actual condición global: las propias concepciones del sistema-mundo -incluidas las respuestas simbólicas a la globalización - también se vuelven factores importantes para determinar las trayectorias de aquel proceso. ${ }^{15}$

15 Giacomo Marramao, Pasaje a Occidente. Filosofía y globalización, Buenos Aires, Katz, 2006, p. 39. 


\section{RELACIÓN ECONÓMICA, POLÍTICA Y DEMOCRÁTICA}

Es necesario señalar que tampoco es menor la importancia que ahora tiene la interconexión planetaria entre los flujos de comunicación y de información. Es decir, la globalidad mediática y telemática ha creado un mercado conformado por redes financieras mundiales que rebasan las fronteras nacionales y regionales, pero también de dominio de las civilizaciones culturales por las naciones neoimperiales capitalistas.

De tal forma, la globalización económica, política, social, cultural y simbólica ha rediseñado el mapa del planeta con manchones de "leopardo virtual e imaginario", entre la opulencia y la miseria, entre la exclusión y la marginación, lo cual puede ser entendido como la conformación de la realidad histórico-social radicada en la desigualdad en un mundo globalizado que ha roto las fronteras territoriales de los Estados en el sistema mundial para la producción y la circulación de bienes de capital, mercancías y seres humanos.

Puede decirse que en esta realidad contemporánea se hace evidente la contradicción, las oposiciones, la confrontación y la lucha de intereses, porque se encuentran cada vez más marcadas las fronteras profundas de eliminación o de desconocimiento social y de marginación.

Ante la situación económica global del capitalismo desigual, excluyente y desolador, es necesario replantear y resemantizar las categorías, los conceptos y los marcos teóricos epistémicos capaces de explicar las prácticas sociales, económicas y filosóficas. Es por ello que debemos resistir y hacer frente al capitalismo global con medios racionales de lucha, pero también con estrategias y alternativas que puedan subvertir el orden global, desestructurante e inequitativo contemporáneo.

Con base en la realidad global, diferentes grupos en el mundo tienen variadas razones para resistirse al capitalismo globalizado neoliberal. Millones de personas padecen las consecuencias del aludido capitalismo. Hombres, mujeres, jóvenes, niños y ancianos sufren desempleo, hambre, miseria, marginación, exclusión y violencia en sus variadas formas. Con el calentamiento global, se da la destrucción de la vida y de la naturaleza, trayendo como consecuencia desesperanza, desolación y muerte.

Por ello, en la realidad contradictoria de oposiciones y resistencias, en el imaginario de los pueblos explotados del mundo, persiste la idea de un "socialismo nuevo", justo y solidario, porque el capitalismo ha avasallado 
la solidaridad humana y, por lo mismo, no puede proveer de justicia y libertad a todos. Aquellos que buscan una sociedad justa, igualitaria, equitativa, solidaria y libre, necesitan atender la construcción de una forma organizativa socialmente concebida, ahí donde la democracia radical vaya más allá de lo procedimental, hacia la participación inclusiva de todos y de todas en los intereses políticos, sociales, económicos y culturales comunes, o sea, en el compromiso de "todos en las cosas de todos".

La lógica geopolítica y democrática que en la actualidad avanza en América Latina, no es incompatible con la lógica de los movimientos sociales y populares. En el horizonte histórico global, la universalización de los derechos y la democracia debieron ser los elementos regulativos de plausibles utopías con un alto nivel de credibilidad. Sin embargo, después de la caída del Muro de Berlín muchos de ellos se amarraron a las figuras de la globalización económica y a los sistemas mediáticos, encaminados hacia las grandes fortunas, ante la realidad histórica latinoamericana y caribeña en que se busca afirmar a través del imaginario colectivo formas comunitarias de participación y de compromiso.

Con la inserción forzada en la globalización y en el neoliberalismo de América Latina y el Caribe, las verdaderas fuerzas democrático-populares y las formas de lucha colectiva han ido tomando conciencia sobre los modos de hacer viable el proyecto democrático-socialista-comunitario, de acuerdo con las características propias de cada país. Al mismo tiempo, se requiere reflexionar sobre la siguiente pregunta: ¿Cómo garantizar los derechos humanos, sociales e individuales, y la manera de enfrentar las fuerzas negadoras de todo principio democrático radical? Ante esta interrogante, puede decirse que la "verdad" de la razón política y de la democrática deberá ser cuestionante y crítica de la realidad sociohistórica actual, incluso, de la propia razón, de la verdad y de la realidad misma. ${ }^{16}$

Asimismo, lo más importante que trae esta globalización, tal y como se ha ejercido, es de un sin sentido muy grande. El único sentido que propicia es el placer, con el hedonismo exacerbado. El hedonismo propicia el consumismo, que es lo que le interesa al mercantilismo; y se llega a la situación en la que se cree que todo puede comprarse, hasta las personas, como ha señalado Baudrillard. Mas tal parece que el placer no alcanza a dar sentido, porque se nota la insatisfacción que eso ha dejado, la desconexión con los demás, esto es, la despreocupación social que los inunda. Para restar efectos a esta globalización que se da en el ámbito económico,

16 Cfr. Sergio Bagú, Tiempo y realidad social y conocimiento, México, Siglo XXI, 1979. 
pero que también abarca lo cultural, tenemos que contar con algún arma para resistir, y esta podrá ser la hermenéutica (analógica-crítica), que la posmodernidad neoconservadora no toma mucho en cuenta, ya que no le interesa el humanismo, sino solamente la ciencia y la técnica en cuanto sirven a sus propósitos mercantilistas. ${ }^{17}$

Esto no es otra cosa que romper con "las razones" que obstruyen la vocación humana, individual-personal y de servicio social-colectivo-comunitario. Es necesario construir democráticamente una realidad más humana y solidaria con todos los latinoamericanos, los caribeños y con el mundo entero. Con toda la humanidad, sin exclusión de nadie.

La realidad espantosa de los últimos años y particularmente con la caída del Muro de Berlín nos obliga a reconstruir teóricamente nuestras concepciones sobre la realidad, sin idealizar demasiado. Se debe cercenar la ideología neoliberal triunfalista, desnudar sus objetivos y alcances e ir también a las propuestas y objetivos no alcanzados por el "socialismo real". Nunca como ahora, no se debe caer en los nubarrones de la falsa conciencia del ejercicio del poder internacional (financiero-especulativo), porque es necesario superar el pesimismo y la desesperación, del mismo modo el trivial optimismo. Porque la vía neocapitalista tampoco es el paraíso, ni el socialismo (anterior) nos da una solución suficiente y adecuada para la superación de la negación de lo eminentemente humano. ${ }^{18}$

Con la conclusión del sistema político bipolar, se ha generado un debilitamiento de los "clivajes" políticos que organizaban las identidades y los conflictos sociales. Esto se puede percibir en la falta de códigos interpretativos, y por lo mismo puede decirse que la realidad y la idea de política han sido observadas en desorden. Los procesos de globalización y de segmentación profundizaron la participación asimétrica de los diversos países en el nuevo sistema mundial y ampliaron la distancia en el interior de cada sociedad, originando sociedades fragmentadas y anómicas.

Ante la realidad global, la filosofía y la ética política de ningún modo pueden ser indiferentes, sobre todo en un mundo de injusticia y rivalidades, de competencia y dominio entre los distintos campos de la vida social globalizada.

17 Mauricio Beuchot, "La hermenéutica en México", en Victórico Muñoz Rosales, (coord.), Filosofía mexicana: retos y perspectivas, México, Editorial Torres, 2009, pp. 74-75.

18 Mario Magallón Anaya, La democracia en América Latina, México, CCyDEL/UNAM/ Plaza y Valdés, 2003, p. 103. 


\section{LOS MASS MEDIA, LA DEMOCRACIA Y LA POLÍTICA HOY}

Evidentemente, en América Latina y el Caribe el clima cultural, político y social, con la autoimplantación de la "cultura posmoderna", ha generado, durante ya casi 40 años, que ésta prevalezca en el imaginario de algunos intelectuales, politólogos, filósofos y políticos, convirtiéndose (dicho en palabras de Hegel) en el "espíritu de la época".

La posmodernidad planteaba, desde la tradición filosófica francesa, cómo la aceleración del tiempo, allí donde hay diversos tiempos políticos, y el ritmo de la vida han devenido vertiginosos, haciendo creer a los individuos que las experiencias del pasado son obsoletas y sólo prevalece un permanente presente, ya "sin pasado y sin futuro".

Las perspectivas del pasado-futuro se han inhabilitado, con lo que no parece existir otro tiempo, más allá de un permanente presente, retrotraído a la política, como al aquí y al ahora históricamente constituidos. La argumentación discursiva racionalmente fundada es reemplazada por imágenes y palabras fugaces mediante la disolvencia de los medios masivos. ${ }^{19}$

Las experiencias totalitarias y excluyentes de finales del siglo XX han provocado en el siglo XXI la necesidad de revalorizar la democracia. Sin embargo, la desaparición de alternativas revolucionarias de cambio, las dinámicas del mercado y la globalización de las comunicaciones parecen alterar la naturaleza de la democracia, cambiando sus condiciones y quedando pendiente su redefinición.

Así, el proceso de cambio ha llevado a una transformación de la política, donde se pueden percibir por lo menos tres rasgos: 1) la pérdida de centralidad de la política. Es decir, se encuentra en entredicho el lugar que ésta tiene en el proceso de desarrollo social caracterizado en la época moderna, concebida como el paso de un orden recibido a otro producido, dicho orden radicaría especialmente en la política; 2) la informatización de la política apunta al desdibujamiento de su anclaje institucional; desborda las formas institucionales y rebasa al sistema político mismo. Allí conviven procesos institucionales como no-institucionales; 3) la articulación de lo público y de lo privado expresa un cambio estructural de la esfera pública y la opinión se desvanece como expresión de la deliberación ciudadana complementaria de las instituciones representativas. Lo público

19 Cfr. Mario Magallón Anaya, La democracia en América Latina. (2a. Ed. corregida y aumentada), México, CIALC/UNAM, 2008. (Aunque apareció publicada hasta 2010.) 
aparece como un "islote" conformado por minorías inconexas. Allí donde hay democracia, las libertades y la justicia deberán ser los factores regulativos de las relaciones políticas.$^{20}$ Es urgente la reconstrucción de la ciudadanía y del sujeto social.

De esta manera, la industria electrónica de comunicación mediática y de internet (Twitter y Facebook) se ha convertido en un factor estratégico importante de cualquier país. El dominio del mundo pasa por el control de aquélla, aunque es innegable que la rectoría hegemónica del sistema mediático global corresponde a los Estados Unidos.

El poder estadounidense de las instituciones privadas sobre la electrónica y los mass media se ha convertido en el brazo mediante el cual los Estados Unidos resuelven sus problemas y consolidan su control del mundo. El predominio tecnológico se encuentra geográficamente en el norte del planeta. Siete países llevan la delantera, seguidos por otros de desarrollo tecnológico medio. En el sótano se ubican los "convidados de piedra", los países subdesarrollados o aquellos que plantean formas de producción y organización económico-social diferentes a las del capitalismo globalizado. ${ }^{21}$

A pesar de este horizonte tan desolador y contradictorio, puede decirse que la única vía para el cambio de la situación social injusta existente en América Latina y el Caribe requiere perseverar en el ejercicio práxico, es decir, en la lucha política concebida como la forma del quehacer humano donde la política y la lucha por la democracia deberán ser la fuerza que impulse los movimientos sociales.

Al respecto, el comunicólogo latinoamericano Manuel Corral considera que:

Insuficiente y todo, la política parece ser la única vía y modo para enfrentar el conflicto de modo racional, a partir de la comunicación, siempre que ésta tenga por contenido el diálogo, la simetría, la libertad entre los sujetos involucrados en el conflicto. Hablar de comunicación, en efecto, es referirse a "todo proceso o relación de carácter dialógico (o diasémico), que requiere para su realización, de un contexto de simetría social en el

\footnotetext{
20 Cfr. Norbert Lechner, "Las transformaciones de la política", en Revista Mexicana de Sociología, núm. 1, enero-marzo, México, Instituto de Investigaciones Económicas, UNAM, 1996.

21 Cfr. Manuel Corral Corral, La comunicación y sus entramados en América Latina, México, Universidad Autónoma del Estado de Nuevo León/Plaza y Valdés, 2003, p. 81 y ss.
} 
que los individuos involucrados tengan las mismas oportunidades para interactuar o coparticipar libremente. ${ }^{22}$

La realidad vivida plantea una serie de interrogantes sobre problemas que no han sido resueltos: la democracia, la justicia, la equidad, la igualdad y la solidaridad humana con los explotados, los excluidos, los miserables, los hambrientos... Para comenzar a resolverlos se requiere de una ética de la emergencia que contrarreste las situaciones extremas que se viven en el mundo global y posmoderno.

Desde una noción liberadora de praxis de las comunidades, de las organizaciones colectivas, de género, se requiere revisar los métodos, las metodologías, las construcciones epistemológicas y ontológicas capaces de explicar nuestra realidad histórica y social como seres en el mundo para abrir nuevos espacios para la compresión del saber popular, comunitario y colectivo.

Para ello, es necesaria la crítica al eurocentrismo, egocentrismo, logocentrismo, que permita realizar relaciones analógicas con las diversas epistemes; efectuar la crítica al concepto de colonialidad del poder y del saber de la teoría crítica del pensamiento latinoamericano; la desconstrucción del desarrollo en América Latina; examinar la tesis de las "culturas híbridas" propuesta por García Canclini; las teorías de la dependencia, de la liberación y libertarias.

Descolonizarnos epistemológica e ideológicamente puede constituir la base para la emancipación intelectual y del colonialismo mental. Si nos emancipamos de la epistemología, fácilmente emanciparemos la economía y la historia. Así pues, nuestro pensamiento dejará de ser siervo de la filosofía, de la ciencia y de la tecnología occidental, para plantear y analizar los problemas desde nuestra realidad, con aportaciones al conocimiento mundial.

Los problemas y los traumas de nuestras naciones sólo son susceptibles de ser solucionados de acuerdo con el análisis crítico de los problemas latinoamericanos y, desde un ejercicio praxológico, éticamente concebido, que asuma el compromiso responsable en la resemantización de los conceptos y de las categorías construidas desde la propia realidad histórica.

Podríamos decir, parafraseando a José Martí, que es tiempo de realizar, ya no la segunda, sino nuestra tercera emancipación mental e independencia, en todos los ámbitos: sociales, científicos, filosóficos y tecnoló-

22 Ibid, p. 93. 
gicos, para ser realmente nosotros mismos, y así aportar al conocimiento mundial.

Es indispensable valorar la actividad humana realizada como seres situados, como seres en el mundo con un horizonte de significación y de sentido, lo cual requiere de interpretar y transformar el mundo en algo más democrático, radicalmente justo y humano.

\section{BiBLIOGRAFÍA}

BAGÚ, S. (1982); Tiempo, realidad social y conocimiento. México: Siglo XXI.

BEUCHOT, M. (2009); "La hermenéutica en México", en Victórico Muñoz Rosales (coord.), Filosofía mexicana: retos y perspectivas. México: Editorial Torres.

CORRAL CORRAL, M. (2003); La comunicación y sus entramados en América Latina. México: Universidad Autónoma del Estado de Nuevo León/Plaza y Valdés.

GONZÁLEZ CASANOVA, P. (1978); Sociología de la explotación. México: Siglo XXI.

JAMESON, F. (2006); Una modernidad singular. Ensayo sobre la ontología del presente. Buenos Aires: Gedisa.

LECHNER, N. (1996); "Las transformaciones de la política", en Revista Mexicana de Sociología, núm. 1, enero-marzo. México: Instituto de Investigaciones Económicas, UNAM.

LEFEBVRE, H. (1972); The Sociology of Marx. Londres: Penguin.

MAGALlón ANAYA, M. (2003); La democracia en América Latina. México: CCyDEL/UNAM/Plaza y Valdés. , (2008); La democracia en América Latina. (2a. ed. corregida y aumentada). México: CIALC/UNAM.

MARRAMAO, G. (2006); Pasaje a Occidente. Filosofía y globalización. Buenos Aires: Katz.

SÁNCHEZ VÁZQUEZ, A. (1983); Sobre filosofía y marxismo. México: UAP.

VALENZUELA FEIJOÓ, J. C. (2006); Libertad y razón. Rousseau, Hegel, Marx. Santiago de Chile: LOM Ediciones/Universidad Metropolitana.

VARGAS LOZANO, G. (1990); ¿Qué hacer con la filosofía en América Latina? México: UAM-Iztapalapa/Universidad Autónoma de Tlaxcala. MORA RUBIO, J. Y RENDÓN ALARCÓN, J. (1983); "Entrevista. Manuel Sacristán habla para Dialéctica. El marxismo ha sido derrotado", en Dialéctica, núm. 13. México. 
VIDAL, G., GUILLÉN A, Y DÉNIZ, J. (2010); “Introducción: América Latina y sus opciones en el curso de la crisis mundial”, Desarrollo y transformación: opciones para América Latina. España: FCE.

VUSKOVIC, P. (1988); "Crisis del desarrollo capitalista y perspectivas del socialismo en América Latina”, en Dialéctica, núm. 20. México: Escuela de Filosofía, Universidad Autónoma de Puebla.

WASSERMAN, C. (2010); "Intelectuales y la cuestión nacional: cinco tesis respecto a la constitución de la nación en América Latina”, en Antonio Escobar Ohmstede, Romana Falcón Vega y Raymond Buve (coords.), La arquitectura histórica del poder. Naciones, nacionalismos y Estados en América Latina. Siglos XVIII, XIX y XX. México: El Colegio de México/Centro de Estudios de Documentación Latinoamericanos. 